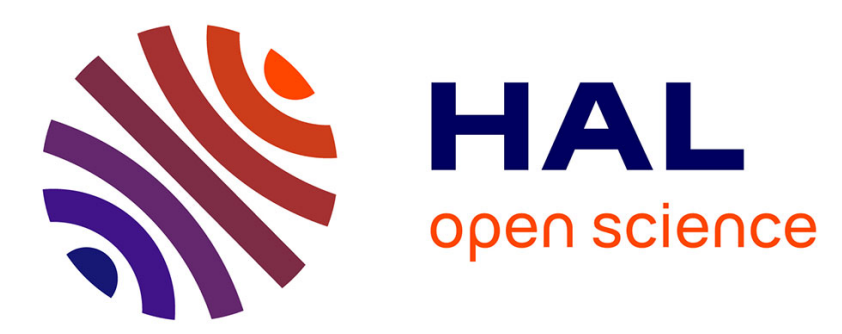

\title{
High Solids Content, Soap-Free, Film-Forming Latexes Stabilized by Laponite Clay Platelets
}

Elodie Bourgeat-Lami, Thiago Rodrigues Guimaraes, Ana Maria Cenacchi

Pereira, Gizelda Maria Alves, Jose Carlos Moreira, Jean-Luc Puteaux, Amilton Martin dos Santos

\section{To cite this version:}

Elodie Bourgeat-Lami, Thiago Rodrigues Guimaraes, Ana Maria Cenacchi Pereira, Gizelda Maria Alves, Jose Carlos Moreira, et al.. High Solids Content, Soap-Free, Film-Forming Latexes Stabilized by Laponite Clay Platelets. Macromolecular Rapid Communications, 2010, 31 (21), pp.1874-1880. 10.1002/marc.201000305 . hal-00723757

\section{HAL Id: hal-00723757 https://hal.science/hal-00723757}

Submitted on 13 Nov 2020

HAL is a multi-disciplinary open access archive for the deposit and dissemination of scientific research documents, whether they are published or not. The documents may come from teaching and research institutions in France or abroad, or from public or private research centers.
L'archive ouverte pluridisciplinaire HAL, est destinée au dépôt et à la diffusion de documents scientifiques de niveau recherche, publiés ou non, émanant des établissements d'enseignement et de recherche français ou étrangers, des laboratoires publics ou privés. 


\title{
High solids content, soap-free, film-forming latexes stabilized by Laponite clay platelets ${ }^{1}$
}

Elodie Bourgeat-Lami, ${ }^{1}{ }^{*}$ Thiago Rodrigues Guimarães, ${ }^{2}$ Ana Maria Cenacchi Pereira, ${ }^{1,2}$

Gizelda Maria Alves, ${ }^{2}$ José Carlos Moreira, ${ }^{2}$ Jean-Luc Putaux, ${ }^{3}$ Amilton Martins dos Santos ${ }^{2 *}$

\begin{abstract}
${ }^{1}$ Université de Lyon, Univ. Lyon 1, CPE Lyon, CNRS, UMR 5265, Laboratoire de Chimie, Catalyse, Polymères et Procédés (C2P2), LCPP group, 43, Bd. du 11 Novembre 1918, F69616 Villeurbanne, France.

${ }^{2}$ Laboratory of Polymer, Department of Chemical Engineering, Lorena Engineering School, University of São Paulo, Estrada Municipal do Campinho, S/N, 12.602.810, Lorena (SP), Brazil.
\end{abstract}

${ }^{3}$ Centre de Recherches sur les Macromolécules Végétales (CERMAV-CNRS), BP 53, F-38041 Grenoble Cedex 9, France - affiliated with Université Joseph Fourier and member of the Institut de Chimie Moléculaire de Grenoble.

*Corresponding Authors

E-mail: bourgeat@ lcpp.cpe.fr, Tel: 33(0)4 7243 17 77, Fax: 33(0)4 72431767

E-mail: amsantos@ dequi.eel.usp.br, Tel: 5512 3159-5049, Fax: 5512 3153-3224

High solids content film-forming poly[styrene-co-(n-butyl acrylate)] [poly(Sty-co-BuA)] latexes armored with Laponite clay platelets have been synthesized by soap-free emulsion copolymerization of styrene and $n$-butyl acrylate. The polymerizations were performed in batch in the presence of Laponite and a methyl ether acrylate-terminated poly(ethylene glycol) macromonomer in order to promote polymer/clay association. The overall polymerization kinetics showed a pronounced effect of clay on nucleation and stabilization of the latex

\footnotetext{
$1 \square$ Supporting information for this article is available at the bottom of the article's abstract page, which can be accessed from the journal's homepage at http://www.macros.wiley-vch.de, or from the author.
} 
particles. Cryo-transmission electron microscopy observation confirmed the armored morphology and indicated that the majority of Laponite platelets were located at the particle surface. The resulting nanostructured films displayed enhanced mechanical properties.

\section{Introduction}

The elaboration of polymer/clay nanocomposites via waterborne processes like emulsion ${ }^{[1-9]}$ or miniemulsion ${ }^{[10-12]}$ polymerizations is attracting increasing interest. These techniques offer the great advantage over solution or bulk polymerization to generate composite latex particles of controlled morphology. ${ }^{[13]}$ In addition, if the organic component is film-forming, such particles can be further used to produce paints or coatings with ordered structures at large scales. ${ }^{[14]}$ Although quite a lot of works have dealt with the use of organically-modified clays, ${ }^{[6-12]}$ pristine clays are also valuable candidates for the elaboration of nanocomposite latexes due to their high swelling capability in water. ${ }^{[1-5]}$ For instance, Lee et al. ${ }^{[1]}$ and Tong et al. $^{[3]}$ reported the successful elaboration of intercalated nanocomposites based on pristine Bentonite and poly(methyl methacrylate), polystyrene (PS) or poly(ethyl acrylate) using an anionic surfactant as stabilizer. Very recently, a number of groups have shown that polymer/clay nanocomposite latexes could also be successfully prepared in the absence of any surfactant. ${ }^{[15-21]}$ For instance, Bon and coworkers reported the efficient synthesis of Laponitearmored polymer latexes by soap-free miniemulsion polymerization. ${ }^{[17]}$ In this process, referred to as "Pickering polymerization" by analogy with the stabilization of emulsions by inorganic solids, ${ }^{[22]}$ the clays adhere to the surface of the miniemulsion droplets, and stabilize the hybrid particles by forming a protecting armor. The ability of inorganic solids to impart colloidal stabilization to polymer latexes is not new. Interest in these systems has emerged in the early 1990s with the pioneering work of Armes and coworkers on the synthesis of silica/vinyl (co)polymer latexes stabilized by ultrafine silica particles. ${ }^{[23-26]}$ Since then, a 
variety of inorganic solids have been reported to be efficient stabilizers in emulsion polymerization. ${ }^{[27-33]}$ Indeed, soap-free emulsion polymerization offers obvious advantages over conventional emulsion polymerization such as ease of purification, due to the absence of surfactant, and improved mechanical and water-resistance properties of the resulting films. However, surprisingly, examples of synthesis of film-forming composite latexes by "Pickering" emulsion polymerization are still sparse. ${ }^{[24,26,27]}$ In addition, almost all clay-armored latexes reported in the literature until now have very low solids contents typically in the 3-20wt\% range with very few exceptions. ${ }^{[34]}$

In this communication, we report an efficient soap-free emulsion polymerization process that allows producing colloidally-stable, high solids content, film-forming Laponite-armored poly(Sty-co-BuA) latexes in one step. The ability of Laponite to stabilize polymer latexes was demonstrated by one of us for the first time three years ago. ${ }^{[28]}$ In this pioneering report, a poly(ethylene glycol) methyl ether methacrylate (PEGMA) macromonomer was used to promote polymer/clay interactions and produce Laponite-armored PS latexes. Herein, an acrylate-terminated PEG macromonomer (PEGA) was selected instead of PEGMA in order to promote fast and efficient anchoring of the growing macroradicals to the clay surface, and warrant the formation of composite latexes free of coagulum. Our communication addresses two challenging issues: i) the efficient formation of colloidally-stable film-forming Laponitearmored latexes, and ii) the increase of the overall solids content up to $40 \mathrm{wt} \%$ with only $5 \mathrm{wt} \%$ added clay.

\section{Experimental Part}

\section{Materials}

The clay particles used in this work were Laponite RD (Rockwood Additives Ltd. U.K.). Laponite is a trioctahedral synthetic hectorite made of discoid platelets with a thickness of 
about $1 \mathrm{~nm}$, a diameter of $25 \mathrm{~nm}$, and a negative surface charge density of $0.014 \mathrm{e}^{-} / \AA^{2} \cdot{ }^{[35]}$ The monomers, styrene (Sty, 98\%, Sigma-Aldrich) and $n$-butyl acrylate (BuA, 99\%, SigmaAldrich) were distilled under vacuum before use. Poly(ethylene glycol) methyl ether acrylate (PEGA, 454g.mol ${ }^{-1}$, Sigma-Aldrich), potassium persulfate (KPS, 99\%, Sigma-Aldrich) and the peptizing agent: sodium pyrophosphate tetrabasic $\left(\mathrm{Na}_{4} \mathrm{P}_{2} \mathrm{O}_{7}, 98 \%\right.$, Synth), were used as received. The water used in all experiments was purified using a Milli-Q Academic system (Millipore Corporation).

\section{Preparation of poly(Sty-co-BuA $) /$ Laponite nanocomposite latexes and films}

The Laponite was dispersed in $130 \mathrm{~mL}$ of water containing the peptizing agent $(10 \mathrm{wt} \%$ based on clay) and stirred for $30 \mathrm{~min}$ in a jacketed vessel cooled to $10^{\circ} \mathrm{C}$, under nitrogen atmosphere. The PEGA macromonomer $(2.1 \mathrm{wt} \%$ based on Laponite) was then added to the clay suspension and left stirring overnight. The Laponite/PEGA suspension was poured into a $200 \mathrm{~mL}$ three-neck double wall reactor equipped with a condenser, a nitrogen purging tube, and a stirrer. The monomers, styrene and $\mathrm{BuA}$ (45:55 by weight), were added and the reaction medium degassed during $20 \mathrm{~min}$. The initiator, KPS $(0.5 \%$ based on monomers, diluted in $20 \mathrm{~mL}$ of deionized water), was finally introduced in the reactor and the polymerization allowed to proceed at $70^{\circ} \mathrm{C}$, under a nitrogen atmosphere for $8 \mathrm{~h}$. Table 1 summarizes the recipes of all experiments carried out in this work. Nanocomposite films were prepared by casting the polymer latexes in silicon moulds at room temperature.

\section{Characterization}

Monomer consumption was followed by gravimetric analysis. The latex particle size was measured by dynamic light scattering (DLS) using a Zetasizer 1000 from Malvern. DMA analyses were carried out using a DMA-2980 TA-Instruments equipment, using the tension 
mode, from -70 to $80^{\circ} \mathrm{C}$, with a heating rate of $3^{\circ} \mathrm{C} / \mathrm{min}$, at a frequency of $1 \mathrm{~Hz}$. According to the method described elsewhere, ${ }^{[9 c, 36]}$ thin films of the suspensions were prepared for cryoTEM on lacy carbon films and vitrified in liquid ethane. The specimens were observed at low temperature with a Philips CM200 'Cryo' microscope operating at $80 \mathrm{kV}$. Images were recorded on Kodak SO163 films. The percentage of surface coverage of the latex particles by the clay platelets was determined as reported elsewhere ${ }^{[17]}$ assuming a 2D square lateral packing of the Laponite disks and using the number-average particle diameter determined by TEM.

\section{Results and Discussion}

Laponite-armored poly(Sty-co-BuA) latexes were successfully produced via soap-free emulsion copolymerization of styrene and BuA in the presence of Laponite RD, using PEGA as mediator. As seen in Table 1, high conversion values were obtained for all experiments. The conversion $v s$. time curves in Figure 1 show that Laponite has a strong effect on the polymerization kinetics as we previously observed for styrene polymerization under similar conditions. ${ }^{[28]}$ The larger the amount of clay in water, the higher the initial polymerization rate.

\section{Insert Table 1 and Figure 1}

Cryo-TEM images of the latex particles formed with different Laponite and solids contents are shown in Figure 2. In all samples, the particles are mostly spheroidal. The Laponite platelets can clearly be seen at the particle surface, forming a dark outline, as discussed in previous articles. ${ }^{[9 c]}$ Only a minor amount of free Laponite platelets was observed in the aqueous phase. They were often located in the vicinity of the armored particles suggesting 
clay-clay interaction at the particle surface. Some latex particles with a more elongated shape were sometimes observed. They probably originated from the coalescence of unstable particles. In that case, clay platelets may have been embedded in the resulting particles as shown in the Supporting Information (Figure S1).

\section{Insert Figure 2}

The diameter of 350-500 particles was measured from cryo-TEM images of the latexes

obtained in runs 2, 3, 5 and 6 (Table 1). We assumed a spherical shape for the particles and discarded the minor population of ellipsoidal ones. Number- and weight-average mean diameters $D_{\mathrm{n}}$ and $D_{\mathrm{w}}$ were calculated and the corresponding size-distribution histograms are given in Figure 2.

The size distribution of particles from run $2(17 \mathrm{wt} \%$ solids content, $5 \mathrm{wt} \%$ clay $)$ is monomodal, with $D_{\mathrm{n}}=220 \pm 54 \mathrm{~nm}\left(D_{\mathrm{w}}=256 \mathrm{~nm}\right)$. The distribution of particles from run 3 $(17 \mathrm{wt} \%$ solids content, $13 \mathrm{wt} \%$ clay) is narrower and the particles are significantly smaller $\left(D_{\mathrm{n}}=98 \pm 28 \mathrm{~nm}, D_{\mathrm{w}}=115 \mathrm{~nm}\right)$. Very small particles with a diameter of 20-30nm were observed (Figures $2 \mathrm{c}$ and $2 \mathrm{~d}$ ) that would correspond to a minor population detected in the histogram. The size distribution of particles from run 5 (30wt $\%$ solids content, $12 \mathrm{wt} \%$ clay) is more clearly bimodal with populations centered around 40 and $160 \mathrm{~nm}$, for a global $D_{\mathrm{n}}$ of $144 \pm 54 \mathrm{~nm}$ $\left(D_{\mathrm{w}}=183 \mathrm{~nm}\right)$. The smallest particles can clearly be seen in Figure 2f. The size distribution from run 6 is also bimodal and displays the largest particle size of the series.

The size measurements have shown that the particle diameter depended on both clay and solids contents. The smallest particles $\left(D_{\mathrm{n}}=98 \mathrm{~nm}\right)$ were obtained for $13 \mathrm{wt} \%$ Laponite and $17 \mathrm{wt} \%$ solids content (run 3) which corresponds to $121 \%$ coverage of the latex particles by the clay platelets. Decreasing the clay content to $5 \mathrm{wt} \%$ (run 2) resulted in bigger particles 
(220nm), indicating that with such a low solids content, $5 \mathrm{wt} \%$ Laponite was sufficient to stabilize the latex particles. In addition, increasing the solids content to $30 \mathrm{wt} \%$ while maintaining the clay content (5wt\%, run 4), resulted in a significant increase in DLS particle diameter (Figure 1b) and a decrease in latex stability. The DLS particle size increased up to $3241 \mathrm{~nm}$ after around 50\% monomer conversion and then decreased to around $1466 \mathrm{~nm}$ once the reaction was complete. This experiment was performed in duplicate and was found to be reproducible (Figure S2). The increase and decrease in particle size were accompanied by a concomitant increase and decrease in viscosity. It is well known that particle aggregation increases the viscosity of suspensions. ${ }^{[37]}$ Therefore, it is possible that for the solids content targeted in this experiment, the amount of Laponite surrounding the newly nucleated particles was not sufficient to maintain their colloidal stability. The composite particles thus aggregated to decrease the surface-to-volume ratio and achieve a minimum surface coverage necessary to get colloidal stability. The subsequent decreases in particle size and viscosity suggest that the aggregation was somehow reversible. Similar results were obtained by Sheibat-Othman during the synthesis of $\mathrm{PS} / \mathrm{SiO}_{2}$ and poly[(styrene-co-(methyl methacrylate) $] / \mathrm{SiO}_{2}$ composite particles by soap-free emulsion polymerization. ${ }^{[33]}$ In agreement with this previous work, the present data suggest that the adsorbed clay platelets form a protecting armor that prevents the latex particles from irreversible aggregation. Interestingly, increasing the clay content to $12 \mathrm{wt} \%$ (run 5) resulted in a significant decrease in particle size, indicating that a minimum amount of clay was required to ensure good colloidal stability.

Considering that achieving high solids contents is an important requirement in the coating industry, we increased the total amount of solids to $40 \mathrm{wt} \%$ using only $5 \mathrm{wt} \%$ Laponite (run 6). This value was a reasonable target for a first evaluation although solids contents of 50-60wt\% or more would be desirable for industrial applications. The clay concentration in water for this 
experiment $\left(31.7 \mathrm{~g} . \mathrm{L}^{-1}\right)$ was intermediate between those used in runs 4 and 5 (Table 1). As expected, the reaction rate was also found to be intermediate between these two experiments. In addition, the polymerization behaved like in run 4: the particle size increased up to around $700 \mathrm{~nm}$ and then slightly decreased to $628 \mathrm{~nm}$. As previously mentioned, the histogram corresponding to this run is bimodal (Figure 2). The particles are the largest in the series and also the most polydisperse. The two populations are approximately centered around 80 and $360 \mathrm{~nm}$, for a global $D_{\mathrm{n}}$ of $290 \pm 134 \mathrm{~nm}\left(D_{\mathrm{w}}=398 \mathrm{~nm}\right)$. The large size again suggests a limited stability of the particles although the latex suspension was considered to be colloidally-stable in the sense that it did not undergo massive flocculation. Besides, we did not observe any increase in viscosity or gelation. Note that increasing further the clay content led to complete loss of latex colloidal stability.

As seen in Table 1, the difference between the diameters measured by DLS and from cryoTEM images is particularly large: the DLS diameters are about 220-250\% larger than the number-average diameters in the case of runs 3, 5 and 6 . This clearly indicates that the suspensions contained large scattering objects most likely due to some aggregation. Aggregation is very difficult to assess in cryo-TEM images. Indeed, the aggregates are thicker than the final embedding film and likely pushed out of the field of view by capillary forces. Moreover, they are located in the areas where the liquid is thick enough to accommodate them but after freezing, the ice film is so thick that it is totally opaque to electrons and unobservable. As the images chosen for the Figures always display the areas of the sample that are transparent enough for interpretation, only individual particles could be seen in these images. Armes and coworkers have previously reported that film-forming latexes stabilized by ultrafine silica particles flocculated when the styrene content in the copolymer was lower than $50 \mathrm{wt} \%{ }^{[26]}$ Increasing the styrene content above $50 \mathrm{wt} \%$ enabled to produce stable latex 
suspensions although the average particle diameter determined by DLS was always 50nm larger than that measured from TEM images. In the present case, particle aggregation might be due to insufficient charge repulsion of the clay-armored particles, which, in turn, can be accounted for by a too low surface coverage or by a too low clay surface charge density. The estimation of the latex surface coverage indicates that, in all cases, there was enough clay platelets to fully cover the particle surface (Table 1). However, the calculation assumes that the platelets are uniform in size and non-aggregated, which is presumably not the case especially for high clay contents and high ionic strengths, as Laponite platelets are known to aggregate in these conditions. ${ }^{[38]}$ Therefore, the number of platelets that participate in particle stabilization might be lower than expected. The higher the amount of clay platelets in water, the more important their aggregation, and the lower the number of platelets stabilizing the latex particles. On the other hand, cryo-TEM revealed the presence of free platelets in the aqueous phase suggesting low clay aggregation efficiencies. These excess platelets surrounding the particles might induce latex particle aggregation by promoting particleparticle interaction. Finally, the observed instability may also be indirectly related to the copolymer composition. Indeed, we did not observe any aggregation in Laponite-armored PS latexes prepared under similar conditions. ${ }^{[28]}$ It could be argued that this is due to the low $T \mathrm{~g}$ of the copolymer as soft particles that would come into contact would undergo irreversible aggregation whereas hard particles would not. However, again, this assumes that the soft copolymer particles are less stable than the previously reported PS latexes. One major difference between the two systems that can potentially explain their different stability is the latex particle size. Indeed, the poly(Sty-co-BuA) copolymer particles are approximately twice smaller than the PS latex particles synthesized using similar clay and solids contents. ${ }^{[28]}$ The low particle size of the poly(Sty-co-BuA)/Laponite composite latexes can be accounted for in terms of a higher particle nucleation efficiency. Indeed, the higher solubility of BuA in water 
compared to styrene, together with the use of PEGA that is assumed to be more reactive than PEGMA, may promote the formation of a larger number of water-soluble oligoradicals that can rapidly be captured by the clay platelets through copolymerization with the adsorbed macromonomer. This would consequently lead to the formation of a larger number of particles that would have a lower surface coverage for similar clay contents, and thus a poorer colloidal stability.

Laponite incorporation inside the nanocomposite latex films led to a noteworthy improvement of the mechanical properties as attested by significant increases in storage moduli in the rubbery state even for low clay contents (Figure S3, Supporting Information). The improvement of mechanical properties was more significant for high clay content and high solids content. This remarkable mechanical reinforcement is consistent with the clay-armored morphology, and can be attributed to the formation of a percolating clay network within the film in agreement with previous results from our group. $\left.{ }^{[9,}, 39-40\right]$ The observed increase in storage modulus with increasing solids content can be tentatively ascribed to differences in the clay network architecture. ${ }^{[40]}$

\section{Conclusion}

High solids content, film-forming Laponite-armored latexes with particle diameters in the 100-300nm range where successfully synthesized by soap-free emulsion copolymerization of styrene and $\mathrm{BuA}$ in the presence of a methyl ether acrylate-terminated poly(ethylene glycol) macromonomer. The polymerization kinetics was strongly dependent on the clay concentration in water. The larger the amount of clay, the higher the polymerization rate. Particle diameters depended on both clay and solids contents. Increasing the solids content from 17 to $30 \mathrm{wt} \%$ for $5 \mathrm{wt} \%$ Laponite had a significant impact on the latex colloidal stability. It was shown that a minimum amount of Laponite was required to obtain stable latexes at high 
solids contents. However, a too large amount of clay induced gelation which is to be correlated with the behavior of aqueous Laponite suspensions. None of the latex suspensions described in this work underwent flocculation. However, the significant difference in average diameters measured by DLS and cryo-TEM indicated the occurrence of aggregation suggesting that some particles may be insufficiently covered by clay. Cryo-TEM showed that most of the Laponite platelets adhered to the polymer particle surface, forming a stabilizing shell while a minor amount of excess platelets was observed in water. Films exhibiting a high optical transparency and a significant mechanical reinforcement were obtained. The significant increase of mechanical properties was explained by the formation of a unique organic/inorganic network structure as previously reported by our group for similar particle morphologies.

Acknowledgements: Amilton Martins Dos Santos wishes to thank the FAPESP and CAPES Brazilian funding agencies for financial support. The authors are indebted to Dr. Muriel Lansalot for her critical reading of the manuscript and for her helpful suggestions.

Received: ((will be filled in by the editorial staff)); Revised: ((will be filled in by the editorial staff)); Published online: ((will be filled in by the editorial staff));

DOI: ((will be filled in by the editorial staff))

Keywords: clay; emulsion polymerization; films; mechanical properties; nanocomposites

[1] [1a] D. C. Lee, L. W. Jang, J. Appl. Polym. Sci. 1996, 61, 1117; [1b] M. W. Noh, D. C. Lee, Polym. Bull. 1999, 42, 619; [1c] M. W. Noh, L. W. Jang, D. C. Lee, J. Appl. Polym. 
Sci. 1999, 74, 179; [1d] T. H. Kim, L. W. Jang, D. C. Lee, H. J. Choi, M. S. Jhon, Macromol. Rapid Commun. 2002, 23, 191

[2] S. Bandyopadhyay, E. Giannelis, A. Hsieh, Polym. Mater. Sci. Eng. 2000, 82, 208.

[3] X. Tong, H. Zhao, T. Tang, Z. Feng, B. Huang, J. Polym. Sci. Part A: Polym. Chem. 2002, 40, 1706.

[4] M. Pan, X. Shi, X. Li, H. Hu, L. Zhang, J. Appl. Polym. Sci. 2004, 94, 277.

[5] G. Diaconu, M. Paulis, J. R. Leiza, Polymer 2008, 49, 2444.

[6] M. Xu, Y. S. Choi, Y. K. Kim, K. H. Wang, I. J. Chung, Polymer 2003, 44, 6387.

[7] P. Meneghetti, S. Qutubuddin, Langmuir 2004, 20, 3424.

[8] H; Li, Y. Yang, Y. Yu, J. Adh. Sci. Technol. 2004, 18, 1759.

[9] [9a] N. Negrete-Herrera, J-M. Letoffe, J-L. Putaux, L. David, E. Bourgeat-Lami. Langmuir 2004, 20, 1564; [9b] N. Negrete-Herrera, J-L. Putaux, L. David, E. BourgeatLami, Macromolecules 2006, 39, 9177; [9c] N. Negrete-Herrera, J-L. Putaux, L. David, F. De Haas, E. Bourgeat-Lami, Macromol. Rapid Commun. 2007, 28, 1567.

[10] Q. Sun, Y. Deng, Z. L. Wang, Macromol. Mater. Eng. 2004, 289, 288.

[11] G. Diaconu, M. Paulis, J. R. Leiza, Macromol. React. Eng. 2008, 2, 80.

[12] R. P. Moraes, T. S. Valera, A. M. Dos Santos, P. C. Oliveira, M. L. C. P. Silva, N. R. Demarquette, J. Appl. Polym. Sci. 2009, 112, 1949.

[13] E. Bourgeat-Lami, M. Lansalot, Adv. Polym. Sci. in press, DOI: 10.1007/12_2010_60.

[14] T. Wang, J. L. Keddie, Adv. Colloid Interface Sci. 2009, 147/148, 319.

[15] Y. S. Choi, M. H. Choi, K. H. Wang, S. O. Kim, Y. K. Kim, I. J. Chung, Macromolecules 2001, 34, 8978.

[16] E. H. Yeom, W. N. Kim, J. K. Kim, S-S. Lee, M. Park, Mol. Cryst. Liq. Cryst. 2004, 425,85 .

[17] S. A. F. Bon, P. J. Colver, Langmuir 2007, 23, 8316. 
[18] D. J. Voorn, W. Ming, A. M. van Herk. Macromolecules 2006, 39, 2137.

[19] K. F. Lin, S. C. Lin, A. T. Chien, C. C. Hsieh, M. H. Yen, C. H. Lee, C. S. Lin, W. Y. Chiu, Y. H. Lee, J. Polym. Sci. Part A: Polym. Chem. 2006, 44, 5572.

[20] J. Zhang, K. Chen, H. Zhao, J. Polym. Sci. Part A: Polym. Chem. 2008, 46, 2632.

[21] S. Guillot, F. Bergaya, C. de Azevedo, F. Warmont, J-F. Tranchant, J. Colloid Interf. Sci. 2009, 333, 563.

[22] S. U. Pickering, J. Chem. Soc. 1907, 91, 2001.

[23] C. Barthet, A. J. Hickey, D. B. Cairns, S. P. Armes, Adv. Mater. 1999, 11, 408.

[24] J. I. Amalvy, M. J. Percy, S. P. Armes, Langmuir 2001, 17, 4770.

[25] J. A. Balmer, A. Schmid, S. P. Armes, J. Mater. Chem. 2008, 18, 5722.

[26] A. Schmid, P. Scherl, S. P. Armes, C. A. P. Leite, F. Galembeck, Macromolecules 2009, 42,3721

[27] Y. Liu, X. Chen, R. Wang, J.H. Xin, Mater. Lett. 2006, 60, 3731.

[28] E. Bourgeat-Lami, N. Negrete Herrera, J-L. Putaux, A. Perro, S. Reculusa, S. Ravaine, E. Duguet, Macromol. Symp. 2007, 248, 213.

[29] J. H. Chen, C-Y. Cheng, W-Y. Chiu, C-F. Lee, N-Y. Liang, Eur. Polym. J. 2008, 44, 3271.

[30] P. J. Colver, C. A. L. Colard, S. A. F. Bon, J. Am. Chem. Soc. 2008, 130, 16850.

[31] H. Liu, C. Wang, Q. Gao, J. Chen, X. Liu, Z. Tong, Mater. Lett. 2009, 63, 884.

[32] X. Song, G. Yin, Y. Zhao, H. Wang, Q. Du, J. Polym. Sci. Part A: Polym. Chem. 2009, 47,5728

[33] N. Sheibat-Othman, E. Bourgeat-Lami, Langmuir 2009, 25, 10121.

[34] G. Diaconu, M. Paulis, J.R. Leiza, Polymer 2008, 49, 2444.

[35] Laponite Technical Bulletin L104/90/A; Laporte Industries Ltd. 1990.

[36] M. Lin, F. Chu, A. Guyot, J-L. Putaux, E. Bourgeat-Lami, Polymer 2005, 46, 1331. 
[37] P. A. Lovell, M. S. El-Aasser, Emulsion Polymerization and Emulsion Polymers, Wiley and Sons, London 1997.

[38] T. Nicolai, S. Cocard, Langmuir 2000, 16, 8189.

[39] R. Ruggerone, C. J. G. Plummer, N. Negrete-Herrera, E. Bourgeat-Lami, J-A. E. Manson, Solid. State Phen. 2009, 151, 30.

[40] J. Faucheu, C. Gauthier, L. Chazeau, J-Y. Cavaillé, V. Mellon, E. Bourgeat-Lami, Polymer 2010, 51, 6. 

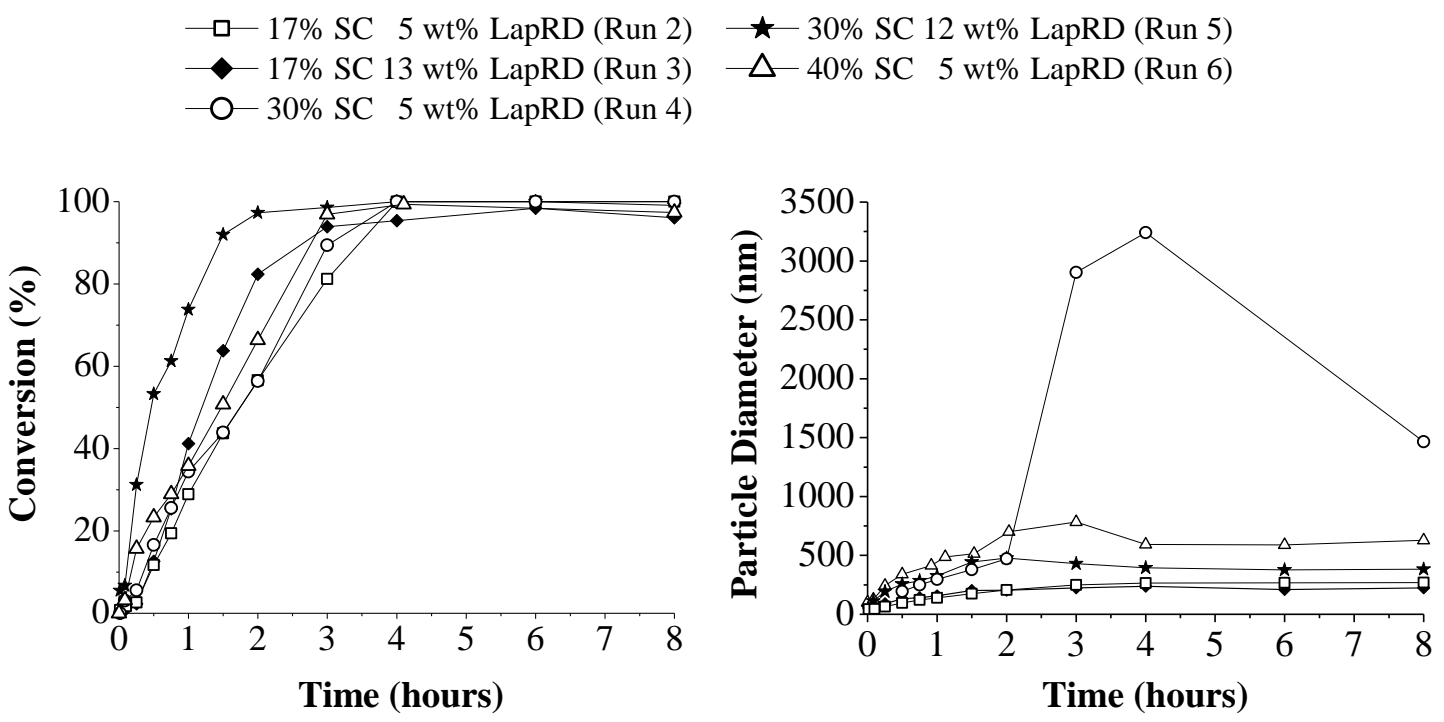

Figure 1. Conversion and particle diameter versus time curves for poly(Sty-co-BuA) latexes with varying Laponite contents and solids contents (SC). 

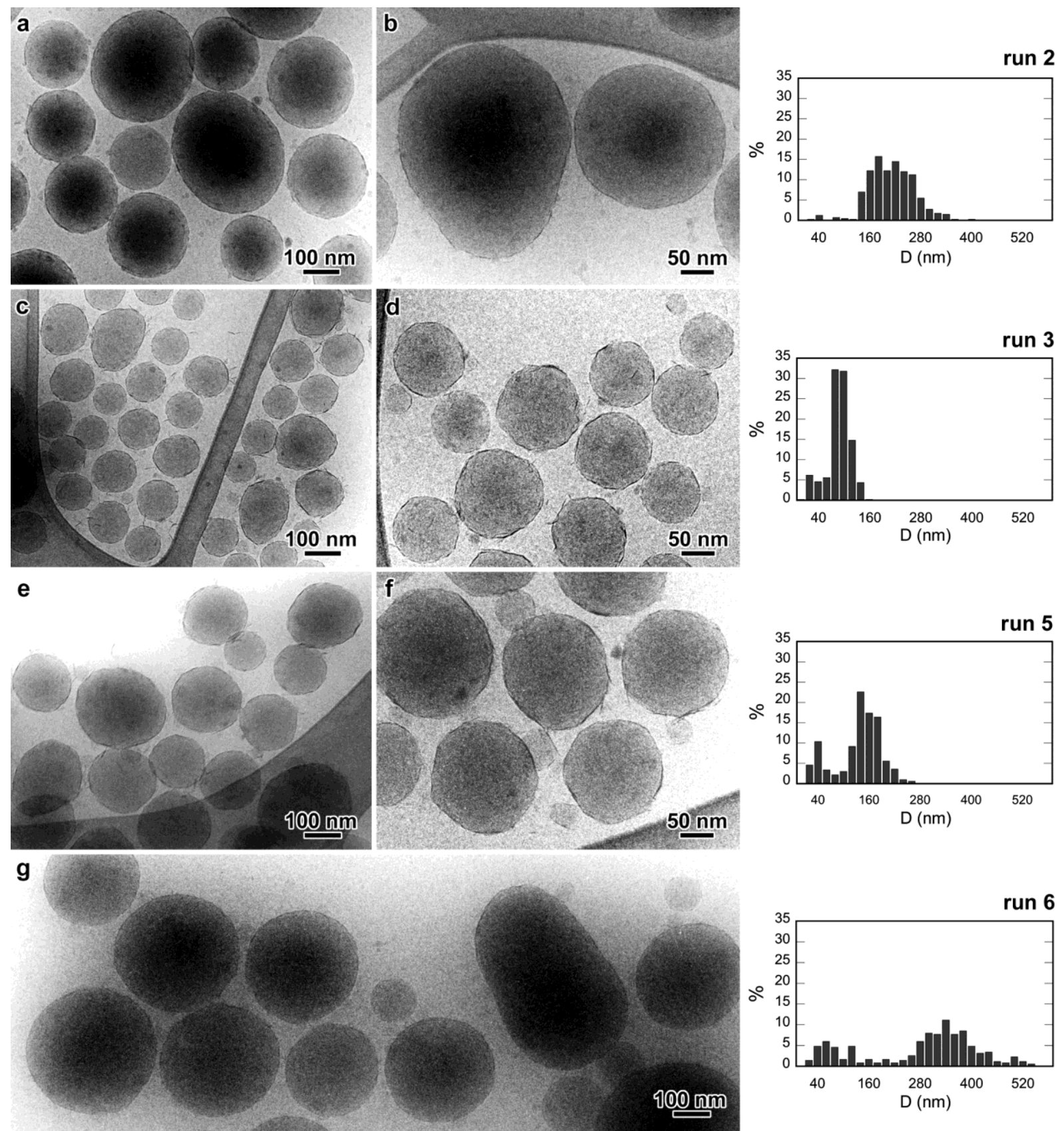

Figure 2. Cryo-TEM images and corresponding size-distribution histograms of Laponitearmored latexes synthesized by surfactant-free emulsion polymerization of styrene and $\mathrm{BuA}$ in the presence of Laponite RD: a, b) run 2; c, d) run 3; e, f) run 5; g) run 6. See Table 1 for sample composition.

(to be displayed over two columns) 
Table 1. Experimental conditions and characteristics of the final latexes obtained by emulsion copolymerization of styrene and BuA in the presence of Laponite RD, with varying Laponite and solids contents.

\begin{tabular}{|c|c|c|c|c|c|c|c|c|c|c|}
\hline Run & $\underset{(\%)^{b)}}{\text { SC }}$ & $\begin{array}{c}\mathrm{BuA} \\
(\mathrm{g})\end{array}$ & $\begin{array}{l}\text { Sty } \\
(\mathrm{g})\end{array}$ & $\begin{array}{r}\text { Laponite } \\
(w t \%)^{c)}\end{array}$ & $\begin{array}{c}\text { Laponite } \\
\left(\text { g. } \mathbf{L}^{-1}\right)\end{array}$ & $\begin{array}{c}\text { Conversion } \\
(\%)\end{array}$ & $D_{\mathrm{h}}(\mathrm{nm})(\mathrm{PDI})^{\mathrm{d})}$ & $\begin{array}{c}D_{\mathbf{n}}(\mathbf{n m}) \\
{[\operatorname{std}(\mathbf{n m})]^{\mathrm{e}}}\end{array}$ & $D_{\mathrm{w}}(\mathbf{n m})^{\mathrm{e})}$ & $\begin{array}{c}\text { Coverage } \\
\left.(\%)^{f}\right)\end{array}$ \\
\hline $1^{\text {a) }}$ & 17 & 16.9 & 13.8 & 0 & 0 & 93.8 & $63(0.01)$ & $\overline{\text { n. d. }}$ & n. d. & - \\
\hline 2 & 17 & 16.6 & 13.5 & 5 & 10 & 100 & $269(0.03)$ & 220 [54] & 256 & 98 \\
\hline 3 & 17 & 16.6 & 13.5 & 13 & 26.6 & 96.1 & $224(0.34)$ & 98 [28] & 115 & 121 \\
\hline 4 & 30 & 35.9 & 29.1 & 5 & 21.7 & 100 & $1466(0.81)$ & n. d. & n. d. & - \\
\hline 5 & 30 & 35.9 & 29.1 & 12 & 52.0 & 99.1 & $383(0.70)$ & 144 [54] & 183 & 155 \\
\hline 6 & 40 & 52.6 & 42.7 & 5 & 31.7 & 97.5 & $628(0.72)$ & 290 [134] & 398 & 133 \\
\hline
\end{tabular}

${ }^{\text {a) }}$ Synthesized by conventional emulsion polymerization, using SDS as surfactant $\left(0.4 \mathrm{wt} \%\right.$ based on water). ${ }^{\text {b) }}$ Overall solids content. ${ }^{\text {c) }}$ Relative percentage of Laponite based on monomers. ${ }^{\mathrm{d})}$ Intensity average diameter and polydispersity index obtained by DLS. ${ }^{\mathrm{e}}$ Number and weight average particle diameters determined from the TEM images by counting 350-500 particles. ${ }^{\text {f) }}$ Calculated as described elsewhere ${ }^{17}$ using the number average particle diameter determined by TEM. n. d.: not determined; std: standard deviation. Water $=150 \mathrm{~g}$, peptizer $=10 \mathrm{wt} \%$ based on Laponite, PEGA $=2.1 \mathrm{wt} \%$ based on Laponite, $\mathrm{KPS}=0.5 \%$ based on monomers, $\mathrm{T}=70^{\circ} \mathrm{C}$. 
DOI: 10/1002

Article Type: Communication

We report on the first successful synthesis of high solids content free-flowing Laponitearmored latexes by soap-free emulsion polymerization. The latexes are cast into nanostructured films with high optical quality and enhanced mechanical properties.
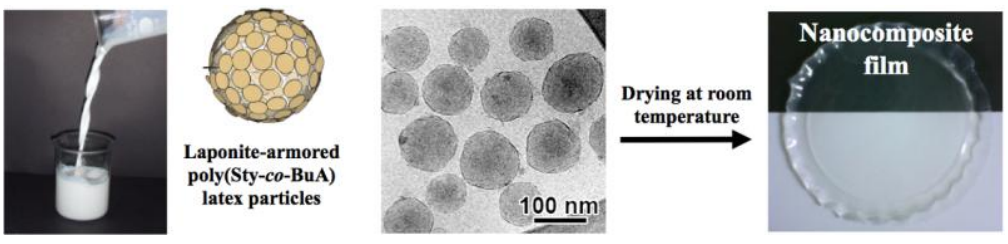

Elodie Bourgeat-Lami, ${ }^{1 *}$ Thiago Rodrigues Guimarães, ${ }^{2}$ Ana Maria Cenacchi Pereira, ${ }^{1,2}$ Gizelda Maria Alves, ${ }^{2}$ José Carlos Moreira, ${ }^{2}$ Jean-Luc Putaux, ${ }^{3}$ Amilton Martins dos Santos ${ }^{2} *$

High solids content, soap-free, film-forming latexes stabilized by Laponite clay platelets 